LETTER TO THE EDITOR

\title{
To be a head and neck surgical trainee in the COVID-19 era. Residents' perspectives after one year of residency 2.0
}

\author{
Specializzarsi in chirurgia testa-collo durante l'era COVID-19. \\ Prospettive degli specializzandi dopo un anno di "specializzazione 2.0" \\ Pietro De Luca, Pasquale Marra, Antonella Bisogno, Donato Troisi, Michele Petrosino, Egidio De Bonis, \\ Matteo Calvanese, Vito Colacurcio \\ Department of Medicine, Surgery and Dentistry. University of Salerno, Italy
}

KEY WORDS: COVID-19, pandemic, residency, surgical residents, otorhinolaryngology

PAROLE CHIAVE: COVID-19, pandemia, specializzazione, specializzandi in chirurgia, otorinolaringoiatria

Dear Editor,

Since February 2020, the spreading of Coronavirus disease (COVID-19) from Wuhan (China) has forced Academic Institutions to reallocate their healthcare personnel into departments dedicated to COVID-19 and to confront unprecedented and long-standing challenges in higher education ${ }^{1}$. The impact of the first wave of the recent pandemic on surgical residency has been considerable, with a dramatic change in our usual workflows and our medical and surgical education never experienced by the previous generations of residents. After one year of the pandemic, what we need to understand is: should we consider this "residency 2.0 " as a standstill, or as a starting point? In trying to answer this question, we provide some food for thought.

As a part of the national plan to flatten the curve of SARS-CoV-2 infections and reduce the impact on local healthcare systems, all non-elective and nonurgent surgical procedures ceased ${ }^{2}$; this reduction leaded to a decrease in residents' involvement in the surgical theatre, with possible negative effects linked to the lack of training, especially for last-year residents. Meanwhile, surgery and dissection courses on the national territory were also suspended, denying trainees the possibility to partially bridge the gap caused by the decrease of surgical procedures. To run for cover, academic institutions dealt contracts with companies that provide online courses and distance learning; online education became viral during the COVID-19 pandemic, with an exponential growth of online classes. Although we participated in many courses at a distance, and we ourselves gave online lectures for medical students, we are deeply convinced that face-to-face interaction will never be matched in quality by other modalities of teaching and learning. We really appreciate this "resident-as-teacher" program and the pride of docere, but we experienced a notable frustration in these non-interpersonal classes, uncertain if this way of interaction with medical students may ensure a full understanding of the concepts explained. We also believe that watching high-quality surgical videos to make up for the significant loss of time in the operating room could be confusing in the long
Received: March 2, 2021

Accepted: March 15, 2021

Published online: May 6, 2021

Correspondence

Pietro De Luca

Department of Medicine, Surgery and Dentistry.

University of Salerno, Italy

E-mail: dr.dlp@hotmail.it

Funding

None.

Conflict of interest

The Authors declare no conflict of interest.

How to cite this article: De Luca P, Marra P, Bisogno A, et al. To be a head and neck surgical trainee in the COVID-19 era. Residents' perspectives after one year of residency 2.0. Acta Otorhinolaryngol Ital 2021;41:383-384. https:// doi.org/10.14639/0392-100X-N1529

(C) Società Italiana di Otorinolaringoiatria e Chirurgia Cervico-Facciale

\section{(c) (1) $(9)$}

This is an open access article distributed in accordance with the CC-BY-NC-ND (Creative Commons Attribution-NonCommercial-NoDerivatives 4.0 International) license. The article can be used by giving appropriate credit and mentioning the license, but only for non-commercial purposes and only in the original version. For further information: https:// creativecommons.org/licenses/by-nc-nd/4.0/deed.en 
run and is not helpful in replacing the lost hours of surgery. Next, most of the elective rotations were also up in the air; indeed, many hospitals denied the possibility of trainees' rotation to avoid the hazardous crowding in departments, with a further reduction in training.

On the other hand, we must absolutely consider that being residents in a global pandemic and the experience gained in the COVID-19 dedicated departments has definitely improved our decision-making and management skills, making us better future leaders.

First of all, we developed better competence in managing patients from home, whenever it was possible. When required to evaluate a patient in person, we gradually refined our skill of gathering personal history before the examination, pressed by the urgent need to minimise as much as possible the risk of a misdiagnosis, and subsequent unnecessary procedures that could be both risky for the personnel involved and for waste of resources in this time of shortages. In addition, visiting patients using face masks, goggles and other inconvenient protective equipment forced us to spend more energy and effort in trying to conduct an appropriate examination: this could reflect in greater confidence when the situation will resume to normal.

Since a nasopharyngeal swab remains the gold standard for specimen sampling and subsequent molecular analysis ${ }^{3}$, ENT trainees were involved in teaching this procedure to healthcare personnel, giving their knowledge of this anatomical location. We were often asked to explain critical anatomic landmarks and we gladly gave tips for a more sensitive and safe test. This had the added benefit of strengthening the relationship with other trainees, specialists and nurses from all branches of medicine, equally involved in the current pandemic. Moreover, all the procedures we had to adopt to contain the spread of the disease will remain in our personal expertise for the times to come. Being able to correctly wear protective equipment, knowing how to organize a ward to avoid contagion, and all the skills we forcibly learned in this year will be precious knowledge for a future cursed by the bad omen of antibiotic resistance and new pandemic diseases. Many residents have also been recruited in the ongoing vaccination campaign, both formally as vaccine administrators, and informally as promoters of a conscious vaccination free from prejudice and fake news ${ }^{4}$. Besides contributing to accelerate a return to normal, it also represented the opportunity to improve the perception of our role as public health officials.

To reschedule appropriate training, we think that in the second and third phase the residency training should focus more on deferred surgical cases, such as sinus surgery, ear surgery and cochlear implants, since not all types of head and neck procedures were affected equally, with necessary prioritisation on urgent procedures. In addition, residency programmes should expand and give priority to hospitals in the training network; in this way, trainees will have the opportunity to try their hand at different realities, even peripheral ones, with a direct approach to the operating room. Finally, during the pandemic we were able to dedicate more time to scientific research, and in line with the literature trend ${ }^{5}$ we decided to focus our efforts on issues related to COVID-19, to help develop better strategies for diagnosis and treatment; in the next future, a substantial amount of time should continue to be dedicated to developing research skills.

After one year of the pandemic, a full restart of surgical residency programs is necessary to bridge the surgical gap created by the COVID-19 pandemic and to avoid that this global crisis will not be a "lesson to be learned". Desperate times call for desperate measures. We sacrificed part of our training with a thought in mind: to make a contribution, however small, in the global fight against COVID-19. Hopefully, this effort will also speed up the return to our residency program.

\section{Acknowledgements}

The authors would like to thank Ettore Cassandro, Chief, Head and Neck Department, University of Salerno (Salerno, Italy), for his critical review and for the leadership during the COVID-19 pandemic.

\section{References}

1 De Luca P, Colacurcio V, De Bonis E, et al. Impact of the COVID-19 pandemic on otolaryngology residency: a real-life experience. Ear Nose Throat J 2020;99:563-564. https://doi. org/10.1177/0145561320926291

2 Ansarin M. Surgical management of head and neck tumours during the SARS-CoV (COVID-19) pandemic. Acta Otorhinolaryngol Ital 2020;40:87-89. https://doi.org/10.14639/0392-100X-N0783

3 Sidiq Z, Hanif M, Dwivedi KK, et al. Laboratory diagnosis of novel coronavirus (2019-nCoV)-present and the future. Indian J Tuberc 2020;67(4S):S128-S131. https://doi.org/10.1016/j.ijtb.2020.09.023

4 Rzymski P, Borkowski L, Drag M, et al. The strategies to support the COVID-19 vaccination with evidence-based communication and tackling misinformation. Vaccines 2021;9:109. https://doi. org/10.3390/vaccines 9020109

5 Nowakowska J, Sobocińska J, Lewicki M, et al. When science goes viral: the research response during three months of the COVID-19 outbreak. Biomed Pharmacother 2020;129:110451. https://doi. org/10.1016/j.biopha.2020.110451 